Undas Vol 12. , Nomor 1, Juni $2016: 27--34$

\title{
ANALISIS TINDAK TUTUR PADA BALIHO KAMPANYE CALON LEGISLATIF PEMILU TAHUN 2009 DI KALIMANTAN SELATAN
}

\author{
Analysis on Baliho Speech Act Campaign Legislative Candidate Election In 2009 \\ In South Kalimantan
}

\author{
Eka Suryatin
}

\author{
Balai Bahasa Kalimantan Selatan \\ Jalan Jenderal Ahmad Yani Km 32,2, Loktabat, Banjarbaru 70712 Kalimantan Selatan \\ Telepon (0511) 4772641, Pos-el: ekasuryatin@yahoo.co.id
}

\begin{abstract}
Abstrak: Penelitian ini membahas bentuk dan maksud tindak tutur pada baliho kampanye legislatif Pemilu tahun 2009 di Kalimantan Selatan. Tujuan penelitian untuk mendeskripsikan bentuk dan maksud tindak tutur pada baliho kampanye legislatif Pemilu tahun 2009 di Kalimantan Selatan. Metode yang digunakan deskriptif kualitatif. Teknik pengumpulan data dilakukan dengan cara teknik simak dan teknik catat. Sumber data penelitian berupa Buku "Lebih Tepat Lebih Baik: Penggunaan Bahasa Indonesia pada Baliho Kampanye Calon Legislatif Pemilu Tahun 2009". Hasil penelitian menunjukkan bahwa pada baliho kampanye calon legislatif pemilu tahun 2009 di Kalimantan Selatan menggunakan tindak tutur lokusi, ilokusi, dan perlokusi. Selain itu, tuturan pada baliho juga menggunakan tindak tutur langsung berupa kalimat perintah dan tindak tutur tak langsung berupa kalimat berita.
\end{abstract}

Kata kunci: Bentuk, maksud, tindak tutur, baliho, kampanye.

Abstract: This study discusses the shape and purpose of the speech act on a billboard campaign in the 2009 legislative elections in South Kalimantan. The research objective to describe the shape and purpose of the speech act on a billboard campaign in the 2009 legislative elections in South Kalimantan. The method used descriptive qualitative. Data was collected by means of techniques and techniques refer to the note. Source of research data in the form of book "More Right Better: Use of Indonesian on Billboard Campaign Legislative Candidate Election Year 2009 ". The results showed that on a billboard campaign Election candidates in 2009 in South Kalimantan, using locutions speech acts, illocutionary, and perlokusi. In addition, the speech on billboards also uses speech act directly in the form of imperative sentences and indirect speech acts in the form of news sentences.

Key words : Form, intention, speech act, billboard, campaign.

\section{PENDAHULUAN}

Bahasa ialah sistem lambang bunyi ujaran yang digunakan untuk berkomunikasi oleh masyarakat lainnya. Bahasa tidak terpisahkan dari manusia dan mengikuti setiap pekerjaannya. Mulai saat bangun pagi sampai malam waktu ia beristirahat, manusia tidak terlepas dari pemakaian bahasa. Manusia yang tidak berbicara pun pada hakikatnya masih menggunakan bahasa, sebab bahasa itu sendiri merupakan alat yang dipakai untuk memenuhi pikiran dan perasaannya, keinginan, dan perbuatan-perbuatan, sekaligus 
Analisis Tindak Tutur pada Baliho Kampanye Calon Legislatif Pemilu Tahun 2009 di Kalimantan Selatan (Eka Suryatin)

sebagai alat yang dipakainya untuk mempengaruhi dan dipengaruhi.

Bahasa memegang peranan penting dalam kehidupan manusia baik itu secara lisan maupun tulisan. Dengan bahasa manusia mampu berkomunikasi antara yang satu dengan yang lainnya. Tidak hanya itu, dengan bahasa manusia juga mampu mengutarakan pendapat, pikiran, dan maksud serta tujuan kepada orang lain. Agar pendapat, pikiran, dan maksud penutur dapat diterima dengan baik oleh lawan tutur diperlukan kaidah, norma, dan etika yang baik.

Kaidah, norma, dan aturan bahasa tulis berbeda dengan bahasa lisan. Bahasa tulis misalnya dalam ranah politik memiliki ciri ragam bahasa yang berbeda dengan bahasa lisan ketika berpidato. Bahasa politik memiliki ciri yang khas biasanya dikemas dengan menggunakan lambang-lambang atau pesan yang dapat mewakili ide atau gagasan penuturnya. Bahasa politik digunakan untuk mengomunikasikan pesan tertulis melalui baliho yang menarik pembaca. Para politisi menggunakan baliho politik dengan tujuan mempengaruhi masyarakat sehingga mendapatkan dukungan dari masyarakat.

Brown dan Levinson (dalam Wijana dan Rohmadi, 2009: 62) menunjukkan secara meyakinkan bahwa penutur menggunakan strategi linguistik yang berbeda-beda di dalam memperlakukan secara wajar lawan tuturnya. Misalnya pada baliho kampanye calon legislatif "Kembalikan Hak Rakyat Sepenuhnya" bisa dijabarkan dengan kajian pragmatik yang akan mengembalikan hak rakyat kembali sepenuhnya jika calon anggota DPRD tersebut terpilih. Melalui tulisan itu penutur menyampaikan kepada mitra tutur untuk mengajak dan memohon untuk memilih calon anggota legislatif Dapil Banjarbaru dan Kab. Banjar supaya terpilih menjadi anggota DPRD.
Bahasa baliho dipandang sebagai bahasa yang efektif untuk menyebarkan visi dan misi dari kandidat calon legislatif. Bentuk tuturan calon legislatif Pemilu Kalimantan Selatan tahun 2009 dikemas dalam bahasa dengan tuturan yang singkat dan menarik. Di dalam tuturan itu banyak terdapat maksud dan tujuan yang sebenarnya ingin disampaikan oleh penutur. Tuturan dalam baliho kampanye calon legislatif pemilu tahun 2009 menarik diteliti karena bahasa pada baliho kampanye calon legislatif tersebut maksud tuturannya mengandung prinsip kesantunan berbahasa. Oleh karena itu, peneliti tertarik untuk meneliti tuturan dalam bahasa baliho kampanye legislatif dengan judul "Analisis Tindak Tutur Bahasa Baliho Kampanye Calon Legislatif Tahun 2009 di Kalimantan Selatan".

Penelitian mengenai baliho kampanye calon legislatif sudah pernah dilakukan di antaranya (lihat: Yayuk (2011) dan Jahdiah (2011). Selain itu, penelitian sejenis pernah dilakukan Handoyo (2014). Yayuk (2011) meneliti Penanda Kesopanan dalam Kampanye Calon Legislatif Berbahasa Banjar Tahun 2009 di Kalimantan Selatan. Yayuk menyatakan calon legislatif menggunakan penanda kesopanan kata ganti dan ungkapan kesopanan seperti permohonan doa dan restu kepada masyarakat agar memilih mereka. Penggunaan kata ganti dan ungkapan permohonan yang menunjukkan kesopanan berbahasa dari para calon legislatif ini sesuai dengan teori kesopanan Leech dan Gu. Sementara itu, Jahdiah (2011) meneliti Wacana Kampanye Politik Calon Legislatif Provinsi Kalimantan Selatan Tahun 2009-2014: Suatu Tinjauan Pragmatik. Jahdiah menyatakan pada wacana kampanye politik calon legistatif tersebut terdapat banyak jenis tindak tutur, di antaranya tindak tutur direktif memohon, meminta, dan mengajak, tindak tutur komisif berjanji menyatakan kesanggupan, dan tindak tutur representatif. 
Handoyo menyatakan ada beberapa bentuk tindak tutur. Tindak tutur lokusi memberiathukan ada 11, ilokusi memberitahukan ada 8 data, perlokusi memberitahukan ada 7 data. Tindak tutur langsung memerintah ada 1 data. Berbeda dengan ketiga penelitian tersebut, penelitian ini membahas tindak tutur yang terdapat dalam bahasa baliho kampanye calon legislatif pemilu tahun 2009 di Kalimantan Selatan.

Masalah yang diangkat dalam penelitian adalah bagaimana bentuk tindak tutur pemakaian bahasa dalam baliho kampanye calon legislatif tahun 2009 di Kalimantan Selatan dalam kajian pragmatik? Apa saja maksud yang terkandung pada tindak tutur bahasa baliho kampanye calon anggota legislatif tahun 2009 di Kalimantan Selatan?

Tujuan dari penelitian adalah mendeskripsikan bentuk tindak tutur pemakaian bahasa dalam baliho kampanye calon legislatif tahun 2009 dalam kajian pragmatik dan mengidentifikasi maksud yang terkandung pada tindak tutur bahasa baliho kampanye calon anggota legislatif tahun 2009 di Kalimantan Selatan.

\section{KERANGKA TEORI}

Menurut Levinson (dalam Tarigan, 1997: 33), pragmatik merupakan telaah mengenai relasi antara bahasa dengan konteks yang merupakan dasar bagi suatu catatan atau laporan pemahaman bahasa. Dengan kata lain, pragmatik adalah telaah mengenai kemampuan pemakai bahasa menghubungkan serta menyerasikan kalimatkalimat dan konteks-konteks secara tepat.

Sementara itu menurut (Yule, 2006: 5), pragmatik adalah studi tentang hubungan antara bentuk-bentuk linguistik dan pemakai bentuk-bentuk itu. Pragmatik adalah studi bahasa yang mendasarkan pijakan analisisnya pada konteks. Konteks yang dimaksud adalah segala latar belakang pengetahuan yang dimiliki bersama oleh penutur dan mitra tutur serta yang menyertai dan mewadahi sebuah pertuturan. Konteks situasi tutur mencakup aspek-aspek tertentu, diantaranya (1) penutur dan lawan tutur, (2) konteks tuturan, (3) tujuan tuturan, (4) tuturan sebagai bentuk tindakan atau aktivitas, dan (5) tuturan sebagai produk tindak verbal (Wijana, 1996: 30).

Searle (dalam Rahardi, 2005: 35-36) menyatakan bahwa dalam praktiknya terdapat tiga macam tindak tutur, antara lain: (1) tindak lokusioner adalah tindak bertutur dengan kata, frasa, dan kalimat sesuai dengan makna yang dikandung oleh kata, frasa, dan kalimat itu. Kalimat ini dapat disebut sebagai the act of saying something. Dalam lokusioner tidak dipermasalahkan maksud dan fungsi tuturan yang disampaikan maksud dan fungsi tuturan yang disampaikan oleh si penutur. Jadi, tuturan "mataku sakit" misalnya, sematamata hanya dimaksudkan memberitahukan si mitra tutur bahwa pada saat dimunculkannya tuturan itu mata penutur sedang dalam keadaan sakit. (2) tindak ilokusioner adalah tindak melakukan sesuatu dengan maksud dan fungsi tertentu pula. Tindak tutur ini dapat dikatakan sebagai the act of doing something. Tuturan "mataku sakit" diucapkan penutur bukan semata-mata dimaksudkan untuk memberitahukan mitra tutur bahwa pada saat dituturkannya tuturan tersebut, rasa sakit sedang bersarang pada mata penutur, namun lebih dari itu bahwa penutur menginginkan mitra tutur melakukan tindakan tertentu berkaitan dengan rasa sakit pada mata penutur, misalnya mitra tutur mengambil tetes mata. (3) tindakan perlokusi adalah tindak menumbuh pengaruh (effect) kepada mitra tutur. Tindak tutur ini disebut dengan the act of affecting someone. Tuturan "mataku sakit", misalnya dapat digunakan untuk menumbuhkan pengaruh (effect) rasa 
Analisis Tindak Tutur pada Baliho Kampanye Calon Legislatif Pemilu Tahun 2009 di Kalimantan Selatan (Eka Suryatin)

takut kepada mitra tutur. Rasa takut itu muncul, misalnya, karena si penutur itu berprofesi sebagai seseorang tukang las yang pada kesehariannya sangat erat dengan kegiatan mengelas.

Selanjutnya, Searle (dalam Rahardi, 2005:36) menggolongkan tindak tutur ilokusi itu ke dalam lima macam bentuk tuturan yang masing-masing memiliki fungsi komunikatif. Kelima macam bentuk tuturan yang menunjukkan fungsi itu dapat dirangkum sebagai berikut.

\section{Asertif (Assertives)}

Bentuk tuturan yang mengikat penutur pada kebenaran proposisi yang diungkapkan, misalnya menyatakan (stating), menyarankan (suggesting), menbual (boasting), mengeluh (complaining), dan mengklaim (claiming).

\section{Direktif (Directives)}

Bentuk tuturan yang dimaksudkan penuturannya untuk membuat pengaruh agar si mitra tutur melakukan tindakan, misalnya, memesan (ordering), memerintah (commanding), memohon (requesting), menasehati (advising), dan merekomendasi (recommending).

\section{Ekspresif (Expressives)}

Bentuk tuturan yang berfungsi untuk menyatakan atau menunjukkan sikap psikologis penutur terhadap suatu keadaan, misalnya berterima kasih (thanking), memberi selamat (congratulating), meminta maaf (pardoning), menyalahkan (blaming), memuji (praising), berbelasungkawa (condoling).

\section{Komisif (Commissives)}

Bentuk tuturan yang berfungsi untuk menyatakan janji atau penawaran, misalnya berjanji (promising), bersumpah (vowing), dan menawarkan sesuatu (offering)

\section{Deklarasi (Declarations)}

Bentuk tuturan yang menghubungkan isi tuturan dengan kenyataan, misalnya berpasrah (resigning), memecat (dismissing), menbaptis (chistening), memberi nama (naming), mengangkat (appointing), mengucilkan (excommicating), dan menghukum (sentencing).

Baliho adalah suatu sarana atau media berpromosi yang mempunyai unsur memberitakan informasi kegiatan yang berhubungan dengan masyarakat luas, selain itu baliho juga digunakan untuk mengiklankan suatu produkbaru (http//riskaajeng.blogspot.co.id/2012/09/bali ho-dan-reklame.html)

Dikenalnya baliho merupakan hasil dari kemajuan ilmu pengetahuan dan teknologi khususnya mesin cetak digital yang semakin canggih. Selain baliho, kadang masyarakat memberikan informasinya bisa melalui pamflet, brosur, buletin, majalah dan lainnya.

\section{METODE PENELITIAN}

Penelitian ini merupakan penelitian kualitatif dengan metode deskriptif. Data dikumpulkan dengan teknik simak dan catat. Setelah data dikumpulkan kemudian data penelitian ini dianalisis menggunakan metode padan pragmatis.

Data penelitian ini berupa wujud, kata, kalimat, dan wacana yang terdapat dalam baliho kampanye calon legislatif Pemilu tahun 2009 di Kalimantan Selatan. Sumber data yang digunakan dalam penelitian ini adalah buku yang berjudul "Lebih Tepat Lebih Baik: Penggunaan Bahasa Indonesia Pada Baliho Kampanye Calon Legislatif Pemilu Tahun 2009)" yang ditulis oleh 
Indrawati dan kawan-kawan tahun 2010.

\section{ANALISIS DAN PEMBAHASAN}

Tuturan pada baliho kampanye calon legislatif pemilu tahun 2009 di Kalimantan Selatan ditemukan dalam bentuk tindak lokusi, ilokusi, dan perlokusi. Selain itu, juga ditemukan tindak tutur langsung yang berupa kalimat perintah dan tindak tutur tak langsung berupa kalimat berita.

\subsection{Tindak lokusi}

Tindak lokusi adalah tindak tutur untuk menyatakan sesuatu. Dalam tindak lukosi, tuturan dilakukan hanya untuk menyatakan sesuatu tanpa ada tendensi atau tujuan lain, apalagi untuk mempengaruhi lawan tuturnya. Dalam baliho kampanye calon legislatif pemilu tahun 2009 di Kalimantan Selatan ditemukan tindak tutur menyatakan sesuatu (lokusi). Berikut cuplikan tindak tutur yang menyatakan sesuatu (lokusi). Wujud tuturan :

PPIB

MUKHTAR LUTFIE

CALON ANGGOTA DPRD NO.

URUT 1

DAPIL KOTA BANJARMASIN 3

(BANJARMASIN UTARA)

(Konteks: dituturkan caleg PPIB kepada masyarakat pengguna jalan yang melewati Banjarmasin)

Data di atas merupakan bentuk tindak tutur lokusi. Bentuk tuturan dalam baliho itu hanya menginformasikan kepada mitra tutur tanpa tendensi mempengaruhi mitra tutur.Tuturan tersebut mempunyai maksud si penutur memberitahukan kepada mitra tutur yang melewati jalan
Banjarmasin bahwa penutur adalah calon anggota DPRD dari partai PIB. Tuturan yang menyatakan atau menginformasikan sesuatu dilihat dari kalimat "Calon anggota DPRD No. Urut 1 dari Partai PIB." Kalimat tersebut bisa dinyatakan sebagai tuturan lokusi karena hanya untuk menyatakan sesuatu tanpa ada tendensi atau tujuan lain, apalagi untuk mempengaruhi lawan tuturnya.

\subsection{Tindak Ilokusi (illocutionary act)}

Tindak ilokusi adalahtindak tutur yang tidak hanya berfungsi untuk menginformasikan sesuatu, tetapi juga untuk melakukan sesuatu. Berdasarkan data yang peneliti peroleh, tindak ilokusi sering digunakan calon legislatif untuk menginformasikan sesuatu supaya lawan tutur melakukan sesuatu. Berikut cuplikan tindak tutur yang menyatakan sesuatu, tetapi juga untuk melakukan sesuatu (ilokusi).

Wujud tuturan :

INGATAKAN, (INGATKAN)

TAHUN DUA RIBU

BUKA SURAT SUARA WARNA

HIJAU

TANDAI NOMOR 9

H. MARDJUKI

CALON ANGGOTA DPRD

BANJAR DARI (MARTAPURA

KOTA, TIMUR, DAN BARAT)

(Konteks: dituturkan caleg DPRD dari partai PPP kepada pembaca baliho yang melewati jalan Martapura)

Data di atas merupakan bentuk tindak tutur ilokusi. Bentuk tuturan dalam baliho itu menginformasikan kepada mitra tutur dan membuat mitra tutur melakukan sesuatu. Tuturan dalam Data tersebut mempunyai maksud si penutur memberitahukan 
Analisis Tindak Tutur pada Baliho Kampanye Calon Legislatif Pemilu Tahun 2009 di Kalimantan Selatan (Eka Suryatin)

kepada mitra tutur yang melewati jalan Martapura bahwa Tahun 2000akan dilaksanakan pemilihan anggota DPRD. Kalimat dalam tuturan itu tidak hanya memberikan informasi kepada pembaca, namun melakukan sesuatu yaitu mengajak pembaca untuk membuka surat suara yang berwarna hijau pada Tahun 2000 dan menandai nomor urut 9. Tuturan yang menyatakan atau menginformasikan sesuatu dilihat dari kalimat "Ingatakan 'ingatkan' tahun dua ribu". Sementara itu, yang menyatakan melakukan sesuatu dilihat dari kalimat "Buka surat suara warna hijau). Kalimat tersebut bisa dinyatakan sebagai tuturan ilokusi karena menyatakan sesuatu dan melakukan sesuatu.

\subsection{Tindak Perlokusi (Perlocutionary act)}

Tindak tutur yang pengutarannya dimaksudkan untuk mempengaruhi lawan tutur. Sebuah tuturan yang diutarakan oleh seseorang seringkali mempunyai daya pengaruh (perlocutionary force) atau efek bagi yang mendengarkannya. Berikut cuplikan tindak tutur yang menginformasikan sesuatu dan mempunyai efek pengaruh bagi yang membacanya (perlokusi).

Wujud Tuturan :

PPRN

PARTAI PEDULI RAKYAT

NASIONAL PILIH NOMOR

URUT 2

NOOR HAYATI

CALEG DPRD KOTA

BANJARMASIN

DAPIL IV BANJARMASIN TIMUR

MEMBEBASKAN RAKYAT DARI

BELENGGU PENDERITAAN

KEMISKINAN, KEBODOHAN,

DAN KETIDAKADILAN.
(Konteks: dituturkan caleg partai PRN kepada pengguna jalan di Banjarmasin)

Data di atas merupakan bentuk tindak tutur perlokusi. Bentuk tuturan dalam baliho itu menginformasikan kepada mitra tutur dan mempunyai daya pengaruh bagi yang membacanya. Tuturan dalam Data tersebut mempunyai maksud si penutur menginformaskan kepada mitra tutur yang melewati jalan Banjarmasin sekaligus mempengaruhi mitra tutur untuk memilihnya. Tuturan yang mempengaruhi pembaca itu dilihat dari kalimat "akan berjuang", kalimat tersebut meyakinkan pembaca jika caleg dari Partai PRN akan berjuang membebaskan rakyat dari belenggu penderitaan kemiskinan, kebodohan, dan ketidakadilan. Kalimat itu dinyatakan sebagai tuturan perlokusi karena dapat mempengaruhi dan meyakinkan pembaca untuk mengikuti apa yang penutur inginkan.

Selain menggunakan tindak lokusi, ilokusi, dan perlokusi tuturan yang terdapat dalam baliho kampanye caleg legislatif Pemilu tahun 2009 juga menggunakan tindak tutur langsung dan tidak langsung.

\subsection{Tindak Tutur Langsung}

Tindak tutur langsung yang terdapat dalam baliho kampanye caleg legislatif Pemilu tahun 2009 adalah tindak tutur langsung yang berdasarkan modusnya berupa kalimat perintah. Berikut cuplikan tindak tutur yang digunakan untuk menyuruh lawan tutur untuk melakukan sesuatu.

Wujud Tuturan :

JANGAN LUPA

PEMILU TANGGAL 9 APRIL 
CONTENGKAN GAMBAR ULUN (SAYA)

USTAZAH HJ. ISNANIAH RUSDI

(IBU I'IS)

KETUA DAN PIMPINAN MAJELIS

ZIKIR RENUNGAN DAN DOA

Data di atas merupakan bentuk tindak tutur langsung yang berdasarkan modusnya berupa kalimat perintah. Bentuk tuturan dalam baliho itu mempunyai maksud memerintahkan kepada mitra tutur untuk memilihnya dengan cara menconteng gambarnya (fotonya) pada pemilu tanggal 9 April.

\subsection{Tindak Tutur Tak Langsung}

Tindak tutur tak langsung yang terdapat dalam baliho kampanye caleg legislatif Pemilu tahun 2009 adalah tindak tutur tak langsung yang berdasarkan modusnya berupa kalimat berita. Tindak tutur tak langsung biasanya digunakan agar seseorang yang diperintah tidak merasa dirirnya diperintah. Berikut cuplikan tindak tutur tak langsung yang digunakan untuk menyuruh lawan tutur untuk melakukan sesuatu.

Wujud Tuturan :

CALON ANGGOTA DPRD

KOTA BANJARBARU

CALON ANGGOTA DPRD NO.

URUT 1

DAPIL 1 BANJARBARU

M. Panca Ikrar Isywara, SE (CACANG)

Penanda: Penutur memberitakan kepada mitra tutur, M.Panca Ikrar
Isywara, SE. calon anggota DPRD No. Urut 1 Dapil Kota Banjarbaru

Data di atas merupakan bentuk tindak tutur tak langsung yang berdasarkan modusnya menggunakan kalimat berita. Bentuk tuturan dalam baliho itu mempunyai maksud memberikan berita kepada mitra tutur bahwa M. Panca Ikrar Isywara, SE. merupakan calon anggota DPRD dengan nomor urut 1 wilayah Dapil Kota Banjarbaru.

\section{PENUTUP}

\subsection{Simpulan}

Baliho Kampanye calon legislatif Pemilu tahun 2009 di Kalimantan Selatan, menggunakan tindak tutur lokusi, ilokusi, dan perlokusi. Selain itu, tuturan pada baliho juga menggunakan tindak tutur langsung dan tindak tutur tak langsung. Tindak tutur langsung berdasarkan modusnya berupa kalimat perintah sedangkan tindak tutur tak langsung yang ditemukan berdasarkan modusnya berupa kalimat berita.

\subsection{Saran}

Penelitian ini hanya bersifat deskriptif dan sangat sederhana sehingga masih bisa dikaji dengan kajian ilmu yang berbeda. Penelitian ini apabila dikaji dengan ilmu yang berbeda akan menambah khazanah ilmu kebahasaan. 
Analisis Tindak Tutur pada Baliho Kampanye Calon Legislatif Pemilu Tahun 2009 di Kalimantan Selatan (Eka Suryatin)

\section{DAFTAR PUSTAKA}

Indrawati, dkk. 2010. Lebih Tepat Lebih Baik: Penggunaan Bahasa Indonesia Pada Baliho Kampanye Calon Legislatif Pemilu Tahun 2009. Banjarbaru: Balai Bahasa Banjarmasin.

Handoyo, Hari Waskito. 2014. Analisis Tindak Tutur Dalam bahasa Iklan Calon Anggota Legislatif Tahun 2014 di Boyolali. Skripsi. Program Pendidikan Bahasa dan Sastra Indonesia Universitas Muhammadiyah Surakarta, Surakarta.

Jahdiah. 2011. Wacana Kampanye Politik Calon Legislatif Provinsi Kalimantan Selatan Tahun 2009-2014: Suatu Tinjauan Pragmatik. Undas. Volume 7. Nomor 1. Hlm. 7.

Rahardi, K. 2005. Pragmatik: Kesantunan Imperatif Bahasa Indonesia. Jakarta: Erlangga.

Rohmadi, Muhammad. 2010. Pragmatik: Teori dan Analisis. Surakarta: Yuma Pustaka.

Sudaryanto. 1993. Metode dan Teknik Analisis Bahasa. Yogyakarta: Duta Wacana.

Tarigan, Henry Guntur. 1997. Pengajaran Pragmatik. Bandung: Angkasa.

Yayuk, Rissari.2011. Penanda Kesopanan dalam Kampanye Calon Legislatif Berbahasa BanjarTahun 2009 di Kalimantan Selatan. Bunga Rampai. Nomor 5. Hlm. 87.

Yule, George. 2006. Pragmatik. Yogyakarta: Pustaka Pelajar.

Wijana, I Dewa Putu. 1996. Dasar-Dasar Pragmatik. Yogyakarta: Andi Offset. dan Rohmadi, Muhammad. 2009. Analisis Wacana Pragmatik: Kajian Teori dan Analisis. Surakarta: Yuma Pustaka.

(http//riskaajeng.blogspot.co.id/2012/09/balisho-dan-reklame.html.) 